\title{
Reciprocal Relationships Between Subjective Age and Retirement Intentions Noémi Nagy
}

Kalaidos University of Applied Sciences and University of South Florida

\author{
Cort W. Rudolph
}

Saint Louis University

Hannes Zacher

Leipzig University

This is a post-review, pre-press version of a manuscript accepted for publication at EJWOP.

Please cite as:

Nagy, N., Rudolph, C.W., \& Zacher, H. (2021, In Press). Reciprocal Relationships Between Subjective Age and Retirement Intentions. European Journal of Work \& Organizational Psychology. doi: 10.1080/1359432X.2021.2016700

\section{Author Note}

Noémi Nagy, Kalaidos University of Applied Sciences Switzerland, Department of Business Psychology Research, Zurich, Switzerland and University of South Florida (FL), USA. Cort W. Rudolph, Department of Psychology, Saint Louis University, St. Louis (MO), USA. Hannes Zacher, Wilhelm Wundt Institute of Psychology, Leipzig University, Leipzig, Germany.

This work was supported by Volkswagen Foundation (Az. 96 849, "The Role of Work in the Development of Civilization Diseases"). Noémi Nagy's work on this paper was supported by a Swiss National Science Foundation funding (SNSF CRSK-1_190820).

Correspondence concerning this article should be addressed to Noémi Nagy: n.nagy.phd@gmail.com 


\begin{abstract}
Organizational researchers and practitioners have become increasingly interested in how subjective age — employees' perceived age — is related to important work and career outcomes. However, the direction of the relationship between employees' subjective age and retirement intentions remains unclear, thus preventing theoretical advances and effective interventions to potentially delay retirement. We contribute to the literature on work and aging by investigating the relationship between subjective age and retirement intentions longitudinally, using a sample of $n=337$ workers who participated in a study with six measurement waves across 15 months. Results of a random intercept cross-lagged panel model show unique between-person and within-person relationships linking subjective age and retirement intentions. As expected, we found a positive relationship between subjective age and retirement intentions at the between-person level of analysis. At the within-person level of analysis, results suggest that retirement intentions positively predicted subjective age, but not vice versa. Overall, these findings contribute to a better understanding of the role of subjective age in the context of work and retirement.
\end{abstract}

Keywords: Subjective Age; Retirement Intentions; Longitudinal Study 


\section{Reciprocal Relationships Between Subjective Age and Retirement Intentions}

As the workforce is aging, organizational researchers and practitioners have become increasingly interested in the way in which people plan for and prepare to enter retirement (e.g., Feldman \& Beehr, 2011; Topa \& Alcover, 2015; Zappalà et al., 2008). To this end, research has looked at relationships between demographic (e.g., Bal et al., 2015; Loretto \& Vickerstaff, 2013; Talaga \& Beehr, 1995) and psychological (e.g., Shacklock \& Brunetto, 2011; Topa \& Alcover, 2015) characteristics and retirement intentions (for meta-analytic reviews, see Topa et al., 2018; Topa et al., 2009). Retirement intentions refer to workers' plans to exit their career jobs (see Adams \& Beehr, 1998) and have been noted as an important antecedent to a variety of retirement behaviors (e.g., retirement planning and decision making; Adams \& Beehr, 1998; Wang \& Shultz, 2010).

Owing in part to often mixed and relatively weak associations between chronological age and work outcomes (for meta-analyses, see Ng \& Feldman, 2008, 2010, 2012), including retirement intentions (Beehr, 2014; Topa et al., 2009), some researchers have shifted focus away from studying chronological age as a predictor of work outcomes, and instead argued for the potentially important role of subjective age (e.g., Kunze et al., 2015; Nagy, Johnston, et al., 2019; Rudolph et al., 2019). Subjective age refers to the perception of one's own chronological age and reflects how age is experienced by the individual (Schwall, 2012).

Although research has established correlations between subjective age and retirement intentions (Cleveland et al., 1997), the directionality of relationships between these variables remains unclear. Most studies in this domain have used cross-sectional or incomplete panel designs that do not allow for the testing of directional hypotheses, the study of dynamic changes in constructs over time, or the separation of relationships at the between- and withinperson levels of analysis. This is problematic because there are strong, theoretically-justified reasons to believe that psychological variables - especially those that reflect judgments of 
oneself and one's future, like subjective age (Eibach et al., 2010; Goecke \& Kunze, 2020) and retirement intentions (Solem et al., 2016; Zacher \& Rudolph, 2017), are likely to be dynamic over time, and potentially exhibit mutually reinforcing relationships with oneanother (Zaniboni et al., 2019).

Accordingly, the primary goal of this study is to better understand the dynamic relationship between subjective age and retirement intentions. We draw from self-perception theory (Bem, 1972) and role theory (Biddle, 1986; Eagly \& Steffen, 1984) to posit hypotheses about dynamic relationships between these variables. Moreover, we address important limitations of previous research, namely the focus on static relationships between subjective age and retirement intentions and the nearly exclusive focus on between-person relationships among these variables. We address these limitations by examining dynamics in both subjective age and retirement intentions longitudinally, the latter being a particularly relevant work-related outcome among older workers in times of demographic change (Adams \& Beehr, 1998; Feldman \& Beehr, 2011). We model both within- and between-person relationships between subjective age and retirement intentions. Importantly, modeling the between-person relationship between subjective age and retirement intentions does not allow conclusions to be drawn about the directionality of this relationship. However, modeling within-person relationships among subjective age and retirement intentions over time affords the ability to understand such directionality, which we argue can be explained by selfperception theory and role theory. Hence, in this study, we draw on these theories to develop hypotheses about the dynamic and reciprocal relationships between subjective age and retirement intentions. Finally, we assess the robustness of our findings when considering age, gender, education, health, income, and core self-evaluations as relevant confounding variables, as called for by previous research concerning relationships between subjective age and work outcomes (Zacher \& Rudolph, 2019a). 
Our research contributes to the work and aging literature in four important ways: First, we provide novel insights into the direction of the relationship between subjective age and retirement intentions by testing hypotheses grounded in theoretical propositions based on role and self-perception theories. More specifically, we address this issue of directionality empirically with our longitudinal research design, which allows for examining the reciprocal interplay of these constructs over six measurement waves. By allowing for the modeling of concurrent time-lagged and cross-lagged relationships, our approach to analyzing these data sheds light on the direction of the within-person effects between subjective age and retirement intentions that are implied by theory.

Second, we employ the recently-advanced random intercept cross-lagged panel model (RI-CLPM; Hamaker et al., 2015) to separately and concurrently model both between-person (i.e., stable over time) and within-person (i.e., dynamic over time) relationships between subjective age and retirement intentions over a timespan of 15 months (see Figure 1 for a graphical depiction of this model). This is important, because nearly all previous research on subjective age in the work domain has considered this variable at the between-person level of analysis only (e.g., Kunze et al., 2015; Nagy, Fasbender, et al., 2019). The few studies that have studied within-person dynamics have investigated either short-term changes (Zacher \& Rudolph, 2019a, 2019b) or daily fluctuations of subjective age (Armenta et al., 2018; Goecke \& Kunze, 2020). Moreover, as retirement is best understood as a process (Feldman \& Beehr, 2011; Wang \& Shultz, 2010), studying within-person dynamics in retirement intentions (and predictors and consequences thereof) is important to ensure a match between theory and methodology.

Third, we respond to calls (e.g., Nagy, Johnston, et al., 2019; Zacher \& Rudolph, $2019 \mathrm{~b}$ ) to better understand the role of subjective age as a psychological representation of the individual aging process, differentiating its effects from potential confounding variables, such 
as chronological age, health, and core self-evaluations. Chronological age and health are closely related to subjective age (Nagy, Johnston, et al., 2019), whereas core self-evaluations reflect people's rather global and fundamental evaluations of themselves (Judge et al., 2003). Core self-evaluations have been shown to confound relationships between subjective age and work outcomes (Zacher \& Rudolph, 2019b), as they influence other, less fundamental and more specific evaluations people make in their lives (e.g., subjective age). Thus, by considering additional sources of confounding variance, we bolster the case for subjective age as an important psychological manifestation of the aging process, which has implications for theory (re)development considering its role among other such variables (e.g., perceived control over the aging process; Lachman, 2006).

Fourth, we contribute to the literature on retirement decision-making, by examining factors that lead to worker retirement intentions or continued labor force participation. Retirement intentions have long been considered important to various aspects of the retirement decision-making process (e.g., Beehr, 1986). Thus, our findings help expand and refine the discussion on the role of subjective age in this process. In addition, we examine not only whether such a relationship exists, but also its direction and incremental predictive value over and above known confounding variables. The current research thus can inform the (re)development of theorizing regarding the dynamics in retirement planning processes.

\section{Theoretical Background and Hypotheses}

Retirement is intuitively considered to be strongly related to chronological age, even in countries and professions without an official retirement age (Beehr, 2014). Despite this, as the workforce is rapidly aging, there is a heightened need for extended careers on both the employees' as well as the employing organizations' part (Fasbender et al., 2014; Shultz \& Wang, 2011). Moreover, careers have also become more protean and idiosyncratic due to globalization, longer tenure in the workforce, and heightened diversity amongst employees 
(Feldman, 1989; Nagy et al., 2016). These developments are accompanied by a general societal uncertainty about the long-term sustainability of the retirement system in most parts of the world (Wang \& Shultz, 2010). Hence, the decision to retire is becoming more complex and multifaceted (Beehr, 2014; Feldman \& Beehr, 2011), as there is an inherent bounded rationality in the retirement decision making process due to incomplete and imperfect information available to those considering retirement (Wang \& Shultz, 2010).

Nevertheless, retirement decision-making is inevitable and there are three broad categories that its predictors can be grouped by: (a) macrolevel societal-, economic and political norms, and regulations; (b) mesolevel job- and organizational as well as familyrelated factors; and (c) microlevel personal factors and individual attributes (Wang \& Shultz, 2010). The current research focuses on the latter, micro-level factors. Microlevel factors are usually the most salient antecedents of retirement decisions (Wang \& Shultz, 2010), with chronological age being the strongest individual-level predictor, followed by health and financial situation (Adams \& Beehr, 1998; Wang et al., 2008).

Although the aging process is a universal phenomenon, there is considerable variation in people’s perception (Barnes-Farrell \& Piotrowski, 1989; Nagy, Fasbender, et al., 2019) and experience (Chang et al., 2019) of aging. Subjective age has been proposed to explain effects of aging beyond the purely chronological marker of age, as perceptions of time and aging are viewed as influential predictors of human behavior and attitudes (Kotter-Gruehn et al., 2016; Weiss \& Weiss, 2019). Subjective age refers to people's perception of their age (Schwall, 2012) or the age people think of themselves as being (Rubin \& Berntsen, 2006); it comprises a subjective evaluation of how old people feel, look, behave, and express interests in different things and activities (Barak, 1987; Kastenbaum et al., 1972). Although chronological age is associated with a number of work-related variables (e.g., retirement intentions), its use as a substantive variable has been criticized as it fails to reflect the 
meanings and beliefs that individuals associate with age (Cleveland \& Hanscom, 2017; Cleveland et al., 1997). Hence, organizational researchers and practitioners have become increasingly interested in how subjective age is related to important work and career outcomes (Kunze et al., 2015; Rudolph et al., 2019). Subjective age has been investigated in relation to various work-related processes (i.e. work motivation, work engagement, employee absenteeism, or burnout; see also Rudolph et al., 2019). While this line of research generally demonstrates that subjective age is correlated with various work outcomes, the direction of these effects is rather unclear given that this research largely relies on cross-sectional data.

\section{Between-Person Relationship of Subjective Age and Retirement Intentions}

Research adopting cross-sectional (i.e., between-person) research designs has found positive relationships between subjective age and retirement intentions. Consistent with roletheory (Eagly \& Steffen, 1984), Barak and Stern (1986) investigated subjective age as a correlate of retirement status and found that retired people perceived themselves as older than other non-retired people of the same chronological age, suggesting that the loss of an important life role might bring about a rise in subjective age. Similarly, Cleveland et al. (1997) tested the distinctiveness and usefulness of perceptual age measures in the work context and found that subjective age accounted for additional variance in retirement intentions, not accounted for by chronological age. More recently, Akkermans et al. (2016) showed an incremental negative relationship between subjective age and workers' motivation to continue to work for their organization. Hence, and in line with previous research findings, our first hypothesis is as follows:

Hypothesis 1: Subjective age is positively related to retirement intentions at the between-person level.

Within-Person Relationships of Subjective Age and Retirement Intentions 
Although research has found positive relationships between subjective age and retirement intentions, there is little evidence of within-person relationships between these constructs. Modeling within-person relationships among these variables enables us to disentangle the directionality of the associations between subjective age and retirement intentions. Moreover, considering such relationships at the within-person level of analysis is important because retirement decision making is understood as a dynamic within-person process that is likely to change over time, and influence and be influenced by other psychological variables that also change over time along with retirement intentions. Similarly, research concerning within-person changes in subjective age suggest that subjective age is not a fixed quality of individuals, but rather that it changes developmentally over the life course (Galambos et al., 2005; Montepare \& Lachman, 1989) as well as idiosyncratically in response to various life- and work events (Armenta et al., 2018; Goecke $\&$ Kunze, 2020). Thus, in the following, we consider reciprocal within-person relationships between subjective age and retirement intentions. As there is not one, unified theoretical model that expects such relationships, we base our predictions of such reciprocal relationships on two existing theoretical perspectives, specifically, self-perception theory and role theory, to shed light on the potential (bi)directionality of this relationship.

The first possible direction of the subjective age — retirement intentions relationship suggests a positive within-person effect from subjective age to retirement intentions. Selfperception theory (Bem, 1972) offers that individuals form attitudes, emotions, and other internal states partially by inferring them from observations of their own behavior. In general, we strive for consistency between our attitudes and our actions and, if that consistency is not given, it is often easier to change our attitudes than our behavior (Festinger, 1957; Greenwald \& Ronis, 1978). In line with this, we argue that workers who feel older are more likely to subsequently intend to retire than workers who feel younger, because a relatively older age is 
more strongly linked to the notion of retirement than a relatively younger age. For instance, a 60-year-old worker who feels 70 years old should be more likely to intend to retire than a 60 year older worker who feels 50 years old, because subjectively and with respect to norms for retirement, being "70 years old" is more strongly associated with retirement than being "50 years old." Thus, we assume that people form intentions regarding retirement based on their subjective perceptions of their age and associated age norms. Hence, according to selfperception theory, people's perceptions of their age (i.e., as relatively older or younger than their actual chronological age) subsequently affect their consideration of retirement related roles (e.g., thinking about retirement vs. staying in the workforce longer). Therefore, our second hypothesis is directional and posits the following:

Hypothesis 2: Subjective age positively predicts retirement intentions at the withinperson level.

The second possible direction of the subjective age-retirement intentions relationship suggests a positive effect from retirement intentions to subjective age. According to role theory (Biddle, 1986; Eagly \& Steffen, 1984), individuals enact various roles in life, which come with certain socially expected behaviors. Role theory offers that much of everyday activity is the acting-out of socially defined roles, each of which are defined by a set of expectations and norms that a person is expected to fulfill. Based on role theory, we expect a positive effect of retirement intentions on subjective age: people who more strongly intend to retire feel subsequently older because thinking about retirement is associated with an "older" role in life. In other words, thinking about retirement subsequently shapes people's attitude and feelings about their own age, because their intentions to retire activate certain age-related assumptions or beliefs (i.e., "people who retire are old"). Therefore, and in compliment to Hypothesis 2, we suggest: 
Hypothesis 3: Retirement intentions positively predict subjective age at the withinperson level.

\section{Method}

\section{Participants and Procedure}

This study was approved by Leipzig University’s Ethical Review Committee (No. 2019.06.25_eb_16, Study Title: Longitudinal Study on Work, Aging and Health). We conducted a longitudinal study with six measurement waves over a total period of 15 months in Germany. The data presented in this article were part of a larger data collection effort. So far, two other articles based on this dataset have been published based on entirely different sets of variables (Röllmann et al., 2021; Rudolph \& Zacher, 2021), and two other manuscripts on entirely different topics and substantive variables are currently under review (n.b. perceived physical health, which represents a control variable in the current study, is a substantive variable in one of these manuscripts). We commissioned a panel management and online research company to recruit participants for this study. Participants were compensated by the company for their time. To ensure sample quality, the company recruits its participants using a variety of sources, from online communities and news portals to members-getmembers campaigns, social media campaigns, and invitations after in-person interviews. All panelists register triple-opt-in and are deemed active according to ISO standards.

For the first measurement wave, $n=5,798$ invitations were sent to potential participants in the company's database. In total, $n=1,152$ persons clicked the survey link and provided basic demographic information. Of these, $n=908$ reported working full-time and provided complete data for our analyses. At the following four measurement waves, complete data for our analyses were provided by $n=718$ (T2), $n=596$ (T3), $n=497$ (T4), and $n=368$ (T5) employees, respectively. The data considered for this study represent the panel of $n=$ 337 responders that provided complete information at all six measurement waves. 
Summary demographics for this $n=337$ sample can be found in Table 1 . At the first measurement wave, in terms of natal sex, this sample included 209 males $(62 \%)$ and 128 females (38\%), ages ranged from 21 to 71 years, and the average age was 44.60 years $(S D=$ 11.70). Average job tenure was 16.60 years $(S D=12.10)$. In terms of educational level, 148 $(43.90 \%)$ held a university degree. Participants worked in a broad range of jobs (e.g., business management and administration, accountancy, education, healthcare, manufacturing).

\section{Measures}

Subjective age. Subjective age was assessed with four items tapping feel, look, act, and interest age (Cleveland et al., 1997; Kastenbaum et al., 1972). Participants were asked to report the age (in years) that best reflects their subjective age in terms of these four aspects. Specifically, after the introductory sentence "Please indicate the age in years that best reflects...", the items were: “... the way you generally feel," “... the way you look or your appearance," “...the age of people whose interests and activities are most like yours," and "...the age that you would most like to be if you could choose your age right now." This measure demonstrated acceptable reliability across all six time points $(\alpha=.882-.879, \omega=$ $.875-.883, \mathrm{AVE}=.642-.661)$

Retirement intentions. Retirement intentions were measured with four items from (Adams \& Beehr, 1998). The items are "I expect to begin collecting a pension in the near future," "I would like to retire in the near future," "I plan to retire in the near future," and "I expect to retire in the near future." This measure demonstrated acceptable reliability across all six time points $(\alpha=.942-.953, \omega=.938-.953, \mathrm{AVE}=.791-.836)$.

Covariates. In an exploratory sensitivity/robustness analysis, we re-specified our focal model controlling for T1 demographic (i.e., age, sex, education, household income) and substantive (i.e., health and core self-evaluations) variables that have been studied in past research concerning subjective age at work and have been found to correlate with either 
subjective age or retirement intentions or confound inferences between subjective age and work-related outcomes. In terms of demographics, chronological age was assessed in years since birth (Schwall, 2012), whereas sex was assessed by asking participants to report their natal sex $(1=$ male; $2=$ female $)$. Education was coded as $0=$ "less than a university education" and 1 = "university education." A single item asking for monthly household income (i.e., in Euros/month) was also collected. In terms of substantive variables, perceived physical health was measured with the 12-item SF-12 survey (Ware et al., 1996; $\alpha=.830$ ). Finally, we measured core self-evaluations using the 12-item scale presented by (Judge et al., $2003 ; \alpha=.602)$.

Analyses. Tests of our hypotheses were embedded in a single random intercept crosslagged panel (RI-CLPM; Hamaker et al., 2015). The RI-CLPM is an extension of the traditional cross-lagged panel model (CLPM) that explicitly models random intercepts that represent between-person variability in addition to concurrently modeling within-person autoregressive and cross-lagged effects. As suggested by Hamaker et al. (2015), traditional CLPMs assume that all variability occurs within-person, and essentially ignores the possibility for "trait like" individual differences to endure across time - a rather strong assumption to make, both practically and theoretically speaking. The RI-CLPM addresses this by explicitly modeling individual's stable scores over all waves (i.e., random intercepts), while simultaneously modeling dynamic scores (i.e., autoregressive and cross-lagged effects). By doing so, the RI-CLPM effectively "separates" stable, between-person components of this model from dynamic, within-person components.

Importantly, the interpretation of autoregressive parameters in the RI-CLPM differs to some extent from a traditional CLPM. In the RI-CLMP, the autoregressive path (i.e., $\mathrm{T}_{\mathrm{k}} \rightarrow$ $\mathrm{T}_{\mathrm{k}+1}$ ) reflects the extent to which within-person deviations in any given modeled variable (e.g., retirement intentions) can be predicted by deviations from one's own expected levels on 
that variable. Importantly, the autoregressive paths exist at the within-person or "state" level in the RI-CLMP (vs. between-person, "trait" level). A significant autoregressive path would suggest that an earlier state of the variable $\left(T_{k}\right)$ predicted future state of the variable $\left(T_{k+1}\right)$.

All models were specified using the R package `lavaan` (Rosseel, 2012). We observed deviations from normality for both subjective age and retirement intentions, thus all models were specified with a robust maximum likelihood estimator (i.e., 'MLR' in `lavaan`; Rosseel, 2012). Accordingly, we report robust (i.e., Huber-White "sandwich") standard errors for parameter estimates (Freedman, 2006) and Yuan-Bentler scaled test statistics (Yuan \& Bentler, 2000). Moreover, tests of nested models rely upon Satorra-Bentler scaled difference tests (Satorra \& Bentler, 2001). To support model fit, we additionally report appropriately scaled variants of fit indices (i.e., CFI, RMSEA, and SRMR). Finally, to address missing item-level data in our measurement models (described below) the full information maximum likelihood ('FIML') variant of 'MLR' was used. Simulations studies have shown that 'FIML' provides unbiased parameter estimates when data are missing at random (MAR; i.e., that a variable's missingness is "ignorable" in that it is unrelated to the variable itself; see Enders and Bandalos (2001).

\section{Results}

Descriptive statistics and correlations are shown in Table 1 and Table 2, respectively. Figure 1 depicts our RI-CLPM model, and relevant parameter estimates. Prior to specifying our focal models to test the hypotheses presented above, we conducted preliminary analyses to address the potential for systematic attrition effects and measurement non-invariance affecting the validity of our results.

\section{Attrition Analysis}

Selection bias is a concern for longitudinal research if patterns of attrition are observed to be systematic (i.e., non-random) over time. Thus, prior to conducting our 
analysis, we considered various formal tests to better understand the nature of attrition across the six waves of our study. Table 1 contains comparisons of demographic and substantive variables measured at T1 between "incomplete responders" $(n=815$; those providing response to T1 only) and the panel of "complete responders" ( $n=337$; those providing complete responses to T1-T6; the focal sample considered here). Participant $\operatorname{sex}\left(\chi_{(1)}^{2}=\right.$ $14.227, p<.001, \Phi=-.115$; females were less likely to be "complete responders" than males) and monthly household income $\left(t_{(726.713)}=-2.001, \mathrm{p}=.046, d=-.130\right.$; "complete responders" had higher monthly income than "incomplete responders") were different between "incomplete responders" and "complete responders." To support these tests, we likewise specified a binary logistic regression model, regressing attrition pattern (i.e., 0 = "incomplete responders" vs. $1=$ "complete responders") onto the variables summarized in Table 1 . This model accounted for $R^{2}$ Cox \& Snell $=.013$ (i.e., $1.30 \%$ ) of the variance in attrition; mirroring the effect suggested above, only sex significantly differentiated attrition patterns $(\mathrm{OR}=0.67$, 95\% CI: $0.51-0.89, p=0.006)$. Despite these observations, given the small effects observed here, we are confident that selection bias in the form of non-random effects of attrition is not a primary concern. We further address the role that participant sex may play in our results via a sensitivity analysis, presented below.

\section{Measurement Invariance Analysis}

Prior to specifying our focal analyses, we also considered longitudinal measurement models to better understand the structure and operations of our measures, and to establish measurement invariance across time. Table 3 summarizes the fit of these models. We followed the advice of Vandenberg and Lance (2000) and Putnick and Bornstein (2016) and fit a series of four CFA models with increasing restrictions imposed upon model parameters (i.e., configural invariance, no restriction; metric invariance, factor loadings constrained to equality; strong invariance, factor loadings and intercepts constrained to equality; strict 
invariance, factor loadings, intercepts, and means constrained to equality). Beyond chi-square difference tests, we observed changes in relative fit indices (i.e., CFI, RMSEA, and SRMR) from model-to-model as evidence for measurement invariance. Supporting measurement invariance, $\Delta \mathrm{CFI}, \triangle \mathrm{RMSEA}, \Delta \mathrm{SRMR}$, observed across all models, were no less than .01 and no greater than .015, respectively (Chen, 2007; Cheung \& Rensvold, 2002). Thus, we are confident that these measures are invariant across time.

\section{Hypothesis Tests}

To test our hypotheses, we specified two RI-CLPM. The first model was specified with freely-estimated over time parameters (i.e., autoregressive and cross-lagged parameters; an "unconstrained model"), whereas the second model constrained these parameters to equality (i.e., a "constrained model"). The fit of the constrained model $\left(\chi^{2} \operatorname{scaled(65)}=91.633, p\right.$ $=.016, \mathrm{CFI}=.992, \mathrm{RMSEA}=.046, \mathrm{SRMR}=.038)$ was not statistically distinguishable from the fit of the unconstrained model $\left(\chi^{2}\right.$ scaled (33) $=71.633, p=.001, \mathrm{CFI}=.992, \mathrm{RMSEA}=.046$, $\mathrm{SRMR}=.038 ; \Delta \chi^{2}$ Satorra-Bentler (32) $=28.852, p=.420$ ). Thus, for the sake of parsimony, we interpret parameter estimates from this constrained model; Table 4 summarizes relevant parameter estimates from this model.

Supporting Hypothesis 1, we observed a positive correlation between the random effects parameters representing stable, between-person levels of subjective age and retirement intentions $\left(r_{x y}=.265, S E=.679, p<.001\right.$; see also Figure 1). Considering Hypotheses 2 and 3 , concerning within-person relationships, we also observed that retirement intentions at $T_{k}$ predict subjective age at $\mathrm{T}_{\mathrm{k}+1}\left(B_{\text {raw }}=.297, S E_{B}=.136, B_{\text {std }}=.074, p=.029\right)$. However, subjective age at $\mathrm{T}_{\mathrm{k}}$ did not predict retirement intentions at $\mathrm{T}_{\mathrm{k}+1}\left(B_{\text {raw }}=.003, S E_{B}=.007, B_{\text {std }}\right.$ $=.016, p=.494$ ). Thus, Hypothesis 3 was supported, whereas Hypothesis 2 was not (see Figure 1). 
Sensitivity Analyses. As a check on the robustness of the conclusions drawn from the focal analyses with respect to demographic and substantive covariates, we conducted a sensitivity analysis wherein we re-specified our focal RI-CLPM with the addition of these control variables. In summary, this sensitivity model fit the data worse than the model without covariates $\left(\chi^{2}\right.$ scaled $(131)=587.375, p<.001, \mathrm{CFI}=.883, \mathrm{RMSEA}=.102, \mathrm{SRMR}=$ .121). However, if we suspend judgment of model fit momentarily, the substantive interpretation of cross-lagged model parameters is equivalent between these models. That is, retirement intentions at $\mathrm{T}_{\mathrm{k}}$ predict subjective age at $\mathrm{T}_{\mathrm{k}+1}\left(B_{\text {raw }}=.289, S E_{B}=.141, B_{\text {std }}=.074\right.$, $p=.040)$, but not vice-versa $\left(B_{\text {raw }}=.003, S E_{B}=.007, B_{\text {std }}=.016, p=.489\right)$. Thus, although model fit suffers with the inclusion of these covariates, one would reach the same conclusions regarding cross-lagged parameter estimates with or without their inclusion. Thus, we are confident that our focal model is appropriately representing the data, and that the conclusions drawn here are robust to these covariates.

Additionally, we ran a sensitivity analysis to check the robustness of our conclusions to "younger worker" versus "older worker" subsets of our sample. Specifically, we split our full sample into two groups (n.b., we chose the cutoff based on the United States Equal Employment Opportunity Commission's, 2021, definition of “older workers”): those younger than 40 years (i.e., "younger workers," $n=130$ ) and those 40 years and older (i.e., "older workers," $n=207$ ) and re-ran our focal analyses within each group. In summary, both models fit the data well ("younger workers": $\chi^{2}$ scaled (65) $=87.179, p=.035, \mathrm{CFI}=.976$, $\mathrm{RMSEA}=.063, \mathrm{SRMR}=.068$; “older workers": $\chi^{2}$ scaled (65) $=101.593, p=.003, \mathrm{CFI}=.980$, $\mathrm{RMSEA}=.065, \mathrm{SRMR}=.050)$. Moreover, whereas the correlation between random effects was significant and positive for "older workers" $\left(r_{x y}=.410\right)$, it was not for "younger workers" $\left(r_{x y}=-.126, p=.162\right)$. More importantly, none of the cross-lagged parameters were statistically significant in either model. That is, retirement intentions at $\mathrm{T}_{\mathrm{k}}$ did not predict 
subjective age at $\mathrm{T}_{\mathrm{k}+1}$ ("younger workers": $B_{\text {raw }}=.293, S E_{B}=.160, B_{\text {std }}=.077, p=.067$; “older workers": $B_{\text {raw }}=.289, S E_{B}=.204, B_{\text {std }}=.069, p=.158$ ), nor vice-versa ("younger workers": $B_{\text {raw }}=-.009, S E_{B}=.013, B_{\text {std }}=-.035, p=.482$; "older workers": $B_{\text {raw }}=.008, S E_{B}$ $\left.=.008, B_{\text {std }}=.034, p=.335\right)$.

Suspending judgement about statistical significance momentarily, it is more important to note here that the parameter estimates derived from both models are largely the same as those derived from the model without restrictions imposed on participant age. Thus, our findings reported here, at least with respect to the within-person level of analysis, are not exclusively an "older worker" phenomenon (i.e., that our conclusions with respect to the direction and magnitude of these cross-lagged effects are not driven exclusively by those 40 years and older in our sample). Moreover, it is important to note too that owing to a reduction in sample size (i.e., $n=337$ in the full sample vs. $n=130$ "younger workers" and $n=207$ "older workers") in this sensitivity analysis, the statistical power to detect significant crosslagged effects is lower than in our focal model. Still, the observation that, at the betweenperson level of analysis, the correlation between subjective age and retirement intentions was nonsignificant for "younger workers" bears further exploration, especially regarding to the distribution of retirement intentions across age groups, over time.

As such, we plotted the means and associated 95\% confidence intervals of retirement intentions of "younger workers" and "older workers" over time (see Figure 2, Panel A). Additionally, we plotted the observed distributions of retirement intentions for both "younger workers" and "older workers" (see Figure 2, Panel B). These two plots provide a sense of how the averages and distributions of retirement intentions vary across age groups and over time, and suggest that there is a strong correspondence among the mean levels of retirement intentions over time and between age groups (i.e., consider the overlapping 95\% confidence intervals over time in Panel A); moreover, there is an appreciable degree of overlap in the 
distributions of retirement intentions between age groups over time (i.e., Panel B). Complete results of these sensitivity analyses are available in our online appendix:

https://osf.io/vhe9n/

Supplemental analysis. Whereas the RI-CLPM adopted here in our focal analysis is an optimal means of understanding cross-lagged effects at the within-person level of analysis, it does not readily allow for one to model conditional effects (e.g., moderators) of such within-person relationships. As such, we additionally conducted a conditional bivariate latent growth model, specifying simultaneous intercepts and slopes for subjective age and retirement intentions, and considering the demographic and substantive covariates described above as predictors of such intercepts and slopes. Although this model does not allow us to test for directional relationships between subjective age and retirement intentions, it does allow us to explore whether demographic and substantive covariates account for average person levels (i.e., intercepts) or within-person trajectories (i.e., slopes) in these variables over time.

In summary, this model fit the data well, $\left(\chi_{\text {scaled (112) }}^{2}=130.380, p=.113, \mathrm{CFI}=.995\right.$, RMSEA $=.022$, SRMR $=.025)$. Chronological age was associated with higher average levels of subjective age over time (i.e., the intercept of subjective age; $B_{\text {raw }}=8.824, S E_{B}=.268, B_{s t d}$ $=.904, p<.001)$ and higher levels of retirement intentions over time (i.e., the intercept of retirement intentions; $\left.B_{\text {raw }}=.335, S E_{B}=.064, B_{s t d}=.353, p<.001\right)$. Likewise, physical health was associated with lower average levels of subjective age over time (i.e., the intercept of subjective age; $\left.B_{\text {raw }}=-.933, S E_{B}=.261, B_{\text {std }}=-.096, p<.001\right)$ and lower levels of retirement intentions over time (i.e., the intercept of retirement intentions; $B_{\text {raw }}=-.247, S E_{B}=.065, B_{\text {std }}$ $=-.260, p<.001)$. Additionally, core self-evaluations were associated with lower average levels of retirement intentions over time (i.e., the intercept of retirement intentions; $B_{\text {raw }}=$ $\left..486, S E_{B}=.074, B_{s t d}=-.511, p<.001\right)$. Education was associated with decreases in 
subjective age over time (i.e., the slope of subjective age, $B_{\text {raw }}=-.152, S E_{B}=.070, B_{\text {std }}=$ $.474, p<.031)$. Thus is, for university educated responders, the slope of subjective age over time was negative, whereas it was otherwise positive for non-university educated responders. No other significant effects of these demographic and substantive covariates on intercepts or slopes for subjective age and retirement intentions were observed. See online appendix for full results: https://osf.io/vhe9n/

\section{Discussion}

Increasing life expectancies and decreasing birth rates in developed countries foreseeably lead to shortages in pension funding systems, meaning that people will have to elongate their working lives and postpone retirement (Cappelli \& Novelli, 2013; Zacher et al., 2018). These challenges posed by the aging workforce necessitate a deeper understanding of successful late career development, to ensure the wellbeing of older workers during their prolonged working lives. Furthermore, the aging and shrinking workforce also poses the threat of knowledge losses and skill shortages in today's economies (Burmeister \& Deller, 2016; Schalk et al., 2010). Hence, this study was undertaken to investigate employees' intentions to remain active in the workforce (vs. retire) and whether and how subjective age affects retirement intentions of employees and vice versa. In support of Hypothesis 1, our findings suggest that there is a positive relationship between subjective age and retirement intentions at the between-person level of analysis. This finding is consistent with previous research (Akkermans et al., 2016; Barak \& Stern, 1986; Cleveland et al., 1997).

Hypotheses 2 and 3 sought to test reciprocal directional relationships between subjective age and retirement intentions at the within-person level of analysis. Partially supporting our predictions, we found that it is not subjective age that predicts retirement intentions (i.e., we did not find support for Hypothesis 2), rather it is retirement intentions that predict subjective age (i.e., supporting Hypothesis 3). This finding is consistent with 
propositions of role theory (e.g., Biddle, 1986; Eagly \& Steffen, 1984), suggesting that people who think more about the role of being a retiree (i.e., those with higher retirement intentions) subsequently perceive themselves as older than their chronological age. In line with role theory, we offer that this is because staying engaged in the workforce is typically (i.e., in a normative sense) associated with younger individuals, whereas the role of a retiree is typically associated with older individuals.

Importantly, these findings were robust to the specification of covariates that serve as potential confounding variables. This is important, as research has often failed to include substantive confounding variables (i.e., health and core self-evaluations; see Nagy, Johnston, et al., 2019; Zacher \& Rudolph, 2019a) when modeling the relationships between subjective age and work outcomes. Importantly too, the observation of non-significant autoregressive paths suggests that state-like aspects of subjective age and retirement intentions at an earlier time $\left(T_{k}\right)$ do not predict states of that variable at a later time $\left(T_{k+1}\right)$. This finding indicates that such state-like qualities of these variable did not endure across our observed occasions; instead, the consistency of that variable across time was due to trait-like elements that are captured in the random intercepts (and the relationship between the random intercepts).

As a whole, the results of this study contribute to an expanded knowledge base regarding factors that encourage individuals working effectively and participating successfully in the labor market across their working lifespan. Moreover, our findings are complimentary to, and expand upon, existing knowledge about dynamics in psychological manifestations of age-related phenomena. For example, our finding that retirement intentions predict subjective age, and not vice versa is consistent with research that has investigated within-person changes in subjective age perceptions (Kotter-Gruehn, 2015; Kotter-Gruehn et al., 2016). Specifically, evidence exists that confronting people with age-related information influences their subjective age perceptions. Eibach et al. (2010) found that an experimental 
manipulation of visual disfluency caused participants to feel significantly older and more susceptible to ageist stereotypes, whereas Kotter-Gruehn et al. (2015) found that negativebut not positive - affect predicted subjective age perceptions in their sample. In line with this, Geraci et al. (2018) found that negative age-relevant feedback on a cognitive test induced changes in subjective age among participants, and the experimental manipulation of Dutt and Wahl (2017) provides evidence that negative mood induction left participants aged 40 and above feeling older. Finally, a recent study showed that engagement in job crafting behaviors predicted changes in subjective age via increases in occupational future time perspective, but not vice versa (Zacher \& Rudolph, 2019b). Hence, while there is experimental evidence from the fields of gerontology and (recently) organizational psychology that subjective age can be manipulated by age-relevant feedback, such as cognitive capacities, grip strength, or future time perspective, we now provide evidence that work-related self-perceptions and roles, such as retirement, also impact subjective age identification.

\section{Limitations and directions for future research}

Although there are notable strengths to our research design and methodology, there are some limitations of this study to note. A potential concern is that we did not measure actual retirement, but retirement intentions. However, as suggested by Adams and Beehr (1998), retirement intentions have both practical and theoretical value, including the fact that actual retirement has a low base rate (see Hanisch \& Hulin, 1991), that retirement intentions often also relate to workers' reduced investments into work (e.g., effort), and that behavioral intentions are a notable proximal precursor to actual behavior. Indeed, research has shown that retirement intentions predict actual retirement entry reasonably well (Henkens \& Tazelaar, 1997; Prothero \& Beach, 1984; Solem et al., 2016). Moreover, not all retirement decisions are voluntary as people might be compelled to work longer than intended due to financial necessities or retire sooner than they would prefer to, because of health issues or 
family obligations. Hence, the voluntariness of the decision to retire represents a boundary condition in the retirement decision making process (Wang \& Shultz, 2010) that we could not study herein. Therefore, we call for future research to include other personal characteristics besides income that are important factors in thinking about retirement (e.g., relationship status, professional and financial situation of partner, partner's attitudes towards retirement and further financial obligations). Additionally, given that all our study variables were assessed via self-report, common method bias could be another concern. However, the temporal separation of the data partly alleviates this concern (Podsakoff et al., 2003).

Another limitation is the generalizability of our study results as the investigated sample was collected in Germany. As there is a state-regulated retirement age Germany, our results might not be fully transferable globally, especially in regard to countries and professions without a state-mandated retirement age. We therefore recommend that future research investigates the cross-cultural applicability of our findings in other countries. Future research is also encouraged to examine the relationship between subjective age and actual retirement. Despite evidence that retirement intentions precede retirement decisions (see also Adams \& Beehr, 1998), longitudinal research could provide stronger evidence for this relationship and look at how different steps of the retirement decision making process, as well as how actual retirement influences subjective age perceptions. In line with this, we call for future research to investigate long-term trajectories of subjective aging along with other variables of interest (e.g., job attitudes; occupational health and wellbeing).

\section{Theoretical and practical implications}

The current study offers support for propositions of role theory. Specifically, the act of thinking about retirement subsequently shapes people's attitude and feelings about their own age. Our results provide support for the notion that thinking about the retirement role (i.e., having stronger intentions to retire) affects the development of one's subjective age, 
specifically feeling subsequently “older” than one's actual chronological age. This result is in line with earlier findings by Zacher and Rudolph (2019b) that an increase in job crafting behaviors lead to lower subjective ages and not vice versa. More broadly, these findings emphasize the importance of the notion of "intentional self-development" from the lifespan psychology literature, which suggests that the selection, pursuit, and adaptation of goals may lead to changes in the individuals' views about self and aging (e.g., Brandtstädter, 1999). Furthermore, Goecke and Kunze (2020) argue that various events can initiate age-related heuristics and increase the salience of age identity and thereby cause younger or older subjective age perceptions.

From a practical perspective, the notion of subjective age might offer new avenues to manage an increasingly aging workforce. For instance, subjective age has been shown to have higher predictive validity than chronological age with regard to work behaviors and outcomes in late career (Nagy, Johnston, et al., 2019). Hence, subjective age could be utilized by organizations as an indicator of work-related wellbeing and fitness and also used in career counselling to examine successful aging of older workers (see also Zacher et al., 2018). Indeed, our study suggests that it may be appropriate to not only consider subjective age as a predictor of work outcomes, but also as an outcome of employees' decisions and plans regarding retirement. As research has shown that "feeling younger" is linked to favorable work outcomes, organizations should avoid practices that make employees "feel old," for instance, age discriminatory practices or promotion of early retirement schemes.

For human resource management (HRM) practice, assessing employees subjective ages could serve as an indicator of successful aging and above-average coping skills in the aging process. This way, HRM would have a "non-invasive" and non-discriminating method and find ways to support the aging workforce as well as provide better targeted support for late career employees. Furthermore, given that retirement intentions influence subjective age 
(but not vice-versa), organizations should place more importance on the topic of retirement decision making, as the retirement intentions of employees do seem to have wider-ranging effects than previously presumed, giving HRM a key role in helping employees with longterm career planning.

Lastly, the malleability of subjective age also provides an interesting avenue to think about successful aging and possibly utilize it in late-career interventions. The findings and theoretical implications of the current study provide a fruitful starting point for creating interventions to target subjective aging.

\section{Conclusion}

Critical research needs for studying an aging workforce include the identification of causal mechanisms and the combination of knowledge from different disciplines. The current study addresses these needs by adopting a research design that more strongly bolsters evidence for causal inferences between subjective age and retirement intentions. Results of our study suggest that, although generally positively correlated at the between-person level of analysis, it is retirement intentions that positively predict subsequent subjective age, and not vice-versa, at the within-person level of analysis. These findings are consistent with our propositions based on role theory, but not self-perception theory. They call into question the assumption that subjective age is a predictor (rather than an outcome) of retirement indentions, and also suggest the need for future research and theory (re)development to adopt a more dynamic, within-person approach to conceptualizing predictors and antecedents of retirement intentions and subjective age. We hope that this study helps researchers and theorists to account for such dynamics appropriately in their future work. 


\section{References}

Adams, G. A., \& Beehr, T. A. (1998). Turnover and retirement: A comparison of their similarities and differences. Personnel Psychology, 51(3), 643-665. https://doi.org/https://doi.org/10.1111/j.1744-6570.1998.tb00255.x

Akkermans, J., de Lange, A. H., van der Heijden, B. I., Kooij, D. T., \& Jansen, P. G. (2016). What about time? Examining chronological and subjective age and their relation to work motivation. Career Development International, 21(4), 419-439. https://doi.org/http://dx.doi.org/10.1108/CDI-04-2016-0063

Armenta, B. M., Scheibe, S., Stroebe, K., Postmes, T., \& Van Yperen, N. W. (2018). Dynamic, not stable: Daily variations in subjective age bias and age group identification predict daily well-being in older workers. Psychology and aging, 33(4), 559. https://doi.org/http://dx.doi.org/10.1037/pag0000263

Bal, P. M., de Lange, A. H., Van der Heijden, B. I. J. M., Zacher, H., Oderkerk, F. A., \& Otten, S. (2015). Young at heart, old at work? Relations between age, (meta)stereotypes, self-categorization, and retirement attitudes. Journal of Vocational Behavior, 91, 35-45. https://doi.org/https://doi.org/10.1016/j.jvb.2015.09.002

Barak, B. (1987). Cognitive age: A new multidimensional approach to measuring age identity. The International Journal of Aging \& Human Development, 25(2), 109-128. https://doi.org/http://dx.doi.org/10.2190/rr3m-vqt0-b911-gqdm

Barak, B., \& Stern, B. (1986). Subjective age correlates: A research note. The Gerontologist, 26(5), 571-578. https://doi.org/https://doi.org/10.1093/geront/26.5.571

Barnes-Farrell, J. L., \& Piotrowski, M. J. (1989). Workers' perceptions of discrepancies between chronological age and personal age: You're only as old as you feel. Psychology and aging, 4(3), 376-377. https://doi.org/http://dx.doi.org/10.1037/0882$\underline{7974.4 .3 .376}$ 
Beehr, T. A. (1986). The process of retirement: A review and recommendations for future investigation. Personnel Psychology, 39(1), 31-55.

https://doi.org/https://doi.org/10.1111/j.1744-6570.1986.tb00573.x

Beehr, T. A. (2014). To retire or not to retire: That is not the question. Journal of Organizational Behavior, 35(8), 1093-1108.

https://doi.org/https://doi.org/10.1002/job.1965

Bem, D. J. (1972). Self-Perception Theory. In Advances in experimental social psychology (Vol. 6, pp. 1-62). Elsevier. https://doi.org/https://doi.org/10.1016/S0065$\underline{2601(08) 60024-6}$

Biddle, B. J. (1986). Recent developments in role theory. Annual Review of Sociology, 12(1), 67-92. https://doi.org/https://doi.org/10.1146/annurev.so.12.080186.000435

Brandtstädter, J. (1999). The self in action and development. In J. Brandtstädter \& R. M. Lerner (Eds.), Action and Self-Development Theroy and Research Through the Life Span (pp. 37-65). Sage Oublications, Inc.

Burmeister, A., \& Deller, J. (2016). Knowledge retention from older and retiring workers: What do we know, and where do we go from here? Work, Aging and Retirement, 2(2), 87-104. https://doi.org/https://doi.org/10.1093/workar/waw002

Cappelli, P., \& Novelli, B. (2013). Managing the older worker: How to prepare for the new organizational order. Harvard Business Press.

Chang, A. Y., Skirbekk, V. F., Tyrovolas, S., Kassebaum, N. J., \& Dieleman, J. L. (2019). Measuring population ageing: an analysis of the global burden of disease study 2017. The Lancet Public Health, 4(3), e159-e167. https://doi.org/https://doi.org/10.1016/S2468-2667(19)30019-2 
Chen, F. F. (2007). Sensitivity of Goodness of Fit Indexes to Lack of Measurement Invariance. Structural Equation Modeling: A Multidisciplinary Journal, 14(3), 464504. https://doi.org/https://doi.org/10.1080/10705510701301834

Cheung, G. W., \& Rensvold, R. B. (2002). Evaluating goodness-of-fit indexes for testing measurement invariance. Structural Equation Modeling: A Multidisciplinary Journal, 9(2), 233-255. https://doi.org/https://doi.org/10.1207/S15328007SEM0902_5

Cleveland, J. N., \& Hanscom, M. (2017). What is old at work? Moving past chronological age. In E. Parry \& J. McCarthy (Eds.), The Palgrave Handbook of Age Diversity and Work (pp. 17-46). Palgrave Macmillan. https://doi.org/https://doi.org/10.1057/978-1$\underline{137-46781-2 \_2}$

Cleveland, J. N., Shore, L. M., \& Murphy, K. R. (1997). Person-and context-oriented perceptual age measures: Additional evidence of distinctiveness and usefulness. Journal of Organizational Behavior, 18(3), 239-251. https://doi.org/http://dx.doi.org/10.1002/(sici)1099-1379(199705)18:3<239::aidjob794>3.0.co;2-a

Dutt, A. J., \& Wahl, H.-W. (2017). Feeling sad makes us feel older: Effects of a sad-mood induction on subjective age. Psychology and aging, 32(5), 412. https://doi.org/https://doi.org/10.1037/pag0000179

Eagly, A. H., \& Steffen, V. J. (1984). Gender stereotypes stem from the distribution of women and men into social roles. Journal of personality and social psychology, 46(4), 735-754. https://doi.org/https://doi.org/10.1037/0022-3514.46.4.735

Eibach, R. P., Mock, S. E., \& Courtney, E. A. (2010). Having a "senior moment": Induced aging phenomenology, subjective age, and susceptibility to ageist stereotypes. Journal of Experimental Social Psychology, 46(4), 643-649. https://doi.org/http://dx.doi.org/10.1016/j.jesp.2010.03.002 
Enders, C. K., \& Bandalos, D. L. (2001). The Relative Performance of Full Information Maximum Likelihood Estimation for Missing Data in Structural Equation Models. Structural Equation Modeling: A Multidisciplinary Journal, 8(3), 430-457. https://doi.org/https://doi.org/10.1207/S15328007SEM0803 5

Fasbender, U., Deller, J., Wang, M., \& Wiernik, B. M. (2014). Deciding whether to work after retirement: The role of the psychological experience of aging. Journal of Vocational Behavior, 84(3), 215-224.

https://doi.org/https://doi.org/10.1016/j.jvb.2014.01.006

Feldman, D. C. (1989). Careers in organizations: Recent trends and future directions. Journal of Management, 15(2), 135-156.

https://doi.org/http://dx.doi.org/10.1177/014920638901500202

Feldman, D. C., \& Beehr, T. A. (2011). A three-phase model of retirement decision making. American Psychologist, 66(1), 193-204. https://doi.org/https://doi.org/10.1037/a0022153

Festinger, L. (1957). A theory of cognitive dissonance (Vol. 2). Stanford University Press. Freedman, D. A. (2006). On the so-called "Huber sandwich estimator" and "robust standard errors". The American Statistician, 60(4), 299-302. https://doi.org/https://doi.org/10.1198/000313006X152207

Galambos, N. L., Turner, P. K., \& Tilton-Weaver, L. C. (2005). Chronological and subjective age in emerging adulthood: The crossover effect. Journal of Adolescent Research, 20(5), 538-556. https://doi.org/http://dx.doi.org/10.1177/0743558405274876

Geraci, L., De Forrest, R., Hughes, M., Saenz, G., \& Tirso, R. (2018). The effect of cognitive testing and feedback on older adults' subjective age. Aging, Neuropsychology, and Cognition, 25(3), 333-350.

https://doi.org/https://doi.org/10.1080/13825585.2017.1299853 
Goecke, T., \& Kunze, F. (2020). "How old do you feel today at work?" Work-related drivers of subjective age in the workplace. European Journal of Work and Organizational Psychology, 1-15. https://doi.org/https://doi.org/10.1080/1359432X.2020.1724098

Greenwald, A. G., \& Ronis, D. L. (1978). Twenty years of cognitive dissonance: Case study of the evolution of a theory. Psychological Review, 85(1), 53-57. https://doi.org/https://doi.org/10.1037/0033-295X.85.1.53

Hamaker, E. L., Kuiper, R. M., \& Grasman, R. P. (2015). A critique of the cross-lagged panel model. Psychological Methods, 20(1), 102-116. https://doi.org/http://dx.doi.org/10.1037/a0038889

Hanisch, K. A., \& Hulin, C. L. (1991). General attitudes and organizational withdrawal: An evaluation of a causal model. Journal of Vocational Behavior, 39(1), 110-128. https://doi.org/https://doi.org/10.1016/0001-8791(91)90006-8

Henkens, K., \& Tazelaar, F. (1997). Explaining retirement decisions of civil servants in the netherlands: Intentions, behavior; and the discrepancy between the two. Research on aging, 19(2), 139-173. https://doi.org/https://doi.org/10.1177/0164027597192001

Judge, T. A., Erez, A., Bono, J. E., \& Thoresen, C. J. (2003). The core self-evaluations scale: Development of a measure. Personnel Psychology, 56(2), 303-331. https://doi.org/http://dx.doi.org/10.1111/j.1744-6570.2003.tb00152.x

Kastenbaum, R., Derbin, V., Sabatini, P., \& Artt, S. (1972). "The ages of me": Toward personal and interpersonal definitions of functional aging. Aging and Human Development, 3(2), 197-211. https://doi.org/http://dx.doi.org/10.2190/TUJR-WTXK866Q-8QU7

Kotter-Gruehn, D. (2015). Changing negative views of aging: Implications for intervention and translational research. Annual Review of Gerontology \& Geriatrics, 35, 167-186. https://doi.org/http://dx.doi.org/10.1891/0198-8794.35.167 
Kotter-Gruehn, D., Kornadt, A. E., \& Stephan, Y. (2016). Looking beyond chronological age: Current knowledge and future directions in the study of subjective age. Gerontology, 62(1), 86-93. https://doi.org/http://dx.doi.org/10.1159/000438671

Kotter-Gruehn, D., Neupert, S. D., \& Stephan, Y. (2015). Feeling old today? Daily health, stressors, and affect explain day-to-day variability in subjective age. Psychology \& Health, 30(12), 1470-1485.

https://doi.org/https://doi.org/10.1080/08870446.2015.1061130

Kunze, F., Raes, A. M., \& Bruch, H. (2015). It matters how old you feel: Antecedents and performance consequences of average relative subjective age in organizations. Journal of Applied Psychology, 100(5), 1511-1526. https://doi.org/http://dx.doi.org/10.1037/a0038909

Lachman, M. E. (2006). Perceived Control Over Aging-Related Declines: Adaptive Beliefs and Behaviors. Current Directions in Psychological Science, 15(6), 282-286. https://doi.org/https://doi.org/10.1111/j.1467-8721.2006.00453.x

Loretto, W., \& Vickerstaff, S. (2013). The domestic and gendered context for retirement. Human Relations, 66(1), 65-86. https://doi.org/https://doi.org/10.1177/0018726712455832

Montepare, J. M., \& Lachman, M. E. (1989). "You're only as old as you feel": Selfperceptions of age, fears of aging, and life satisfaction from adolescence to old age. Psychology and aging, 4(1), 73-78. https://doi.org/http://dx.doi.org/10.1037/0882$\underline{7974.4 .1 .73}$

Nagy, N., Fasbender, U., \& North, M. S. (2019). Youthfuls, Matures, and Veterans: Subtyping subjective age in late career employees. Work, Aging and Retirement, Special Issue: Work and the Multitude of Age Constructs. https://doi.org/http://dx.doi.org/10.1093/workar/waz015 
Nagy, N., Johnston, C., \& Hirschi, A. (2019). Do we act as old as we feel? An examination of subjective age and job crafting behaviour of late career employees. European Journal of Work and Organizational Psychology.

\section{https://doi.org/http://dx.doi.org/10.1080/1359432X.2019.1584183}

Nagy, N., Johnston, C. S., \& Hirschi, A. (2016). Career development and aging. In N. A. Pachana (Ed.), Encyclopedia of Geropsychology. Springer Science+Business Media. https://doi.org/http://dx.doi.org/10.1007/978-981-287-080-3_329-1

Ng, T. W., \& Feldman, D. C. (2008). The relationship of age to ten dimensions of job performance. Journal of Applied Psychology, 93(2), 392-423. https://doi.org/http://dx.doi.org/10.1037/0021-9010.93.2.392

Ng, T. W., \& Feldman, D. C. (2010). The relationship of age with job attitudes: A metaanalysis. Personnel Psychology, 63, 677-718.

https://doi.org/http://dx.doi.org/10.1111/j.1744-6570.2010.01184.x

Ng, T. W., \& Feldman, D. C. (2012). Evaluating six common stereotypes about older workers with meta-analytical data. Personnel Psychology, 65, 821-858. https://doi.org/http://dx.doi.org/10.1111/peps.12003

Podsakoff, P. M., MacKenzie, S. B., Lee, J.-Y., \& Podsakoff, N. P. (2003). Common method biases in behavioral research: A critical review of the literature and recommended remedies. Journal of Applied Psychology, 88(5), 879-903. https://doi.org/http://dx.doi.org/10.1037/0021-9010.88.5.879

Prothero, J., \& Beach, L. R. (1984). Retirement decisions: Expectation, intention, and action. Journal of Applied Social Psychology, 14(2), 162-174. https://doi.org/https://doi.org/10.1111/j.1559-1816.1984.tb02228.x

Putnick, D. L., \& Bornstein, M. H. (2016). Measurement invariance conventions and reporting: The state of the art and future directions for psychological research. 
Developmental Review, 41, 71-90.

https://doi.org/http://dx.doi.org/10.1016/j.dr.2016.06.004

Röllmann, L., Weiss, M., \& Zacher, H. (2021). Does voice benefit or harm occupational well-being? The role of job insecurity. British Journal of Management, 32(3), 708724. https://doi.org/10.1111/1467-8551.12471

Rosseel, Y. (2012). Lavaan: An R package for structural equation modeling and more. Version 0.5-12 (BETA). Journal of statistical software, 48(2), 1-36. https://doi.org/https://doi.org/10.18637/jss.v048.i02

Rubin, D. C., \& Berntsen, D. (2006). People over forty feel $20 \%$ younger than their age: Subjective age across the lifespan. Psychonomic Bulletin \& Review, 13(5), 776-780. https://doi.org/https://dx.doi.org10.3758/BF03193996

Rudolph, C. W., Kunze, F., \& Zacher, H. (2019). Getting objective about subjective age: Introduction to a special issue. Work, Aging and Retirement, 5(4), 265-272. https://doi.org/https://doi.org/10.1093/workar/waz019

Rudolph, C. W. \& Zacher, H. (2021). Age-inclusive human resource practices, age diversity climate, and work ability: Exploring between- and within-person indirect effects. Work, Aging and Retirement, 7(4), 387-403. https://doi.org/10.1093/workar/waaa008

Satorra, A., \& Bentler, P. M. (2001). A scaled difference chi-square test statistic for moment structure analysis. Psychometrika, 66(4), 507-514. https://doi.org/https://doi.org/10.1007/BF02296192

Schalk, R., Van Veldhoven, M., De Lange, A. H., De Witte, H., Kraus, K., StamovRossnagel, C., Tordera, N., Van der Heijden, B., Zappala, S., Bal, M., \& others. (2010). Moving European research on work and ageing forward: Overview and agenda. European Journal of Work and Organizational Psychology, 19, 76-101. https://doi.org/10.1080/13594320802674629 
Schwall, A. R. (2012). Defining age and using age-relevant constructs. In J. Hedge \& W. Borman (Eds.), The Oxford handbook of work and aging (pp. 169-186). Oxford University Press.

https://doi.org/http://dx.doi.org/10.1093/oxfordhb/9780195385052.001.0001

Shacklock, K., \& Brunetto, Y. (2011). A model of older workers' intentions to continue working. Personnel Review, 40, 252-274.

https://doi.org/https://doi.org/10.1108/00483481111106110

Shultz, K. S., \& Wang, M. (2011). Psychological perspectives on the changing nature of retirement. American Psychologist, 66, 170. https://doi.org/10.1037/a0022411

Solem, P. E., Syse, A., Furunes, T., Mykletun, R. J., De Lange, A., Schaufeli, W., \& Ilmarinen, J. (2016). To leave or not to leave: retirement intentions and retirement behaviour. Ageing \& Society, 36(2), 259-281.

https://doi.org/https://doi.org/10.1017/S0144686X14001135

Talaga, J. A., \& Beehr, T. A. (1995). Are there gender differences in predicting retirement decisions? Journal of Applied Psychology, 80(1), 16.

https://doi.org/http://dx.doi.org/10.1037/0021-9010.80.1.16

Topa, G., \& Alcover, C.-M. (2015). Psychosocial factors in retirement intentions and adjustment: a multi-sample study. Career Development International, 20(4), 384-408. https://doi.org/https://doi.org/10.1108/CDI-09-2014-0129

Topa, G., Depolo, M., \& Alcover, C.-M. (2018). Early retirement: a meta-analysis of its antecedent and subsequent correlates. Frontiers in Psychology, 8, 2157. https://doi.org/https://doi.org/10.3389/fpsyg.2017.02157

Topa, G., Moriano, J. A., Depolo, M., Alcover, C.-M., \& Morales, J. F. (2009). Antecedents and consequences of retirement planning and decision-making: A meta-analysis and 
model. Journal of Vocational Behavior, 75(1), 38-55.

https://doi.org/https://doi.org/10.1016/j.jvb.2009.03.002

United States Equal Employment Opportunity Commission. (2021). The Age Discrimination in Employment Act of $1967 . \quad$ Retrieved from

https://www.eeoc.gov/statutes/age-discrimination-employment-act-1967

Vandenberg, R. J., \& Lance, C. E. (2000). A review and synthesis of the measurement invariance literature: Suggestions, practices, and recommendations for organizational research. Organizational Research Methods, 3(1), 4-70.

https://doi.org/https://doi.org/10.1177/109442810031002

Wang, M., \& Shultz, K. S. (2010). Employee retirement: A review and recommendations for future investigation. Journal of Management, 36(1), 172-206.

https://doi.org/https://doi.org/10.1177/0149206309347957

Wang, M., Zhan, Y., Liu, S., \& Shultz, K. S. (2008). Antecedents of bridge employment: A longitudinal investigation. Journal of Applied Psychology, 93(4), 818-830. https://doi.org/https://doi.org/10.1037/0021-9010.93.4.818

Ware, J. E., Kosinski, M., \& Keller, S. D. (1996). A 12-item short-form health survey: Construction of scales and preliminary tests of reliability and validity. Medical Care, 34(3), 220-233. https://doi.org/10.1097/00005650-199603000-00003

Weiss, D., \& Weiss, M. (2019). Why people feel younger: Motivational and social-cognitive mechanisms of the subjective age bias and its implications for work and organizations. Work, Aging and Retirement, 5(4), 273-280.

https://doi.org/https://doi.org/10.1093/workar/waz016

Yuan, K.-H., \& Bentler, P. M. (2000). Three likelihood-based methods for mean and covariance structure analysis with nonnormal missing data. Sociological 
Methodology, 30(1), 165-200. https://doi.org/https://doi.org/10.1111/0081$\underline{1750.00078}$

Zacher, H., Kooij, D. T., \& Beier, M. E. (2018). Successful aging at work: Empirical and methodological advancements. Work, Aging and Retirement, 4(2), 123-128. https://doi.org/https://doi.org/10.1093/workar/way002

Zacher, H., \& Rudolph, C. W. (2017). Change in job satisfaction negatively predicts change in retirement intentions. Work, Aging and Retirement, 3(3), 284-297. https://doi.org/http://dx.doi.org/10.1093/workar/wax009

Zacher, H., \& Rudolph, C. W. (2019a). Just a mirage: On the incremental predictive validity of subjective age. Work, Aging and Retirement, wax031. https://doi.org/https://doi.org/10.1093/workar/wax031

Zacher, H., \& Rudolph, C. W. (2019b). Why do we act as old as we feel? The role of occupational future time perspective and core self-evaluations in the relationship between subjective age and job crafting behaviour. European Journal of Work and Organizational Psychology, 28(6), 831-844.

https://doi.org/https://doi.org/10.1080/1359432X.2019.1677609

Zaniboni, S., Bertolino, M., \& Steiner, D. D. (2019). Relating subjective age to work and non-work outcomes. Psicologia sociale, 14(1), 39-56. https://doi.org/http://dx.doi.org/10.1482/92926

Zappalà, S., Depolo, M., Fraccaroli, F., Guglielmi, D., \& Sarchielli, G. (2008). Postponing job retirement? Psychosocial influences on the preference for early or late retirement. Career Development International, 13(2), 150-167. https://doi.org/http://dx.doi.org/10.1108/13620430810860558 
Table 1. Summary of Demographic Characteristics of Complete and Incomplete Responders.

\begin{tabular}{|c|c|c|c|}
\hline & $\begin{array}{c}\text { Incomplete } \\
(\mathbf{N}=\mathbf{8 1 5})\end{array}$ & $\begin{array}{c}\text { Complete } \\
(\mathrm{N}=337)\end{array}$ & p-value \\
\hline \multicolumn{4}{|l|}{ Sex } \\
\hline Male & $390(47.9 \%)$ & $209(62.0 \%)$ & $<0.001$ \\
\hline Female & $397(48.7 \%)$ & $128(38.0 \%)$ & \\
\hline Missing & $28(3.4 \%)$ & $0(0 \%)$ & \\
\hline \multicolumn{4}{|l|}{ Age (Years) } \\
\hline Mean (SD) & $43.9(13.2)$ & $44.6(11.7)$ & 0.384 \\
\hline Median [Min, Max] & $44.0[19.0,81.0]$ & $45.0[21.0,71.0]$ & \\
\hline Missing & $27(3.3 \%)$ & $0(0 \%)$ & \\
\hline \multicolumn{4}{|l|}{ Job Tenure (Years) } \\
\hline Mean (SD) & $16.0(12.3)$ & $16.6(12.1)$ & 0.445 \\
\hline Median [Min, Max] & $12.0[0,50.0]$ & $13.0[0,47.0]$ & \\
\hline Missing & $180(22.1 \%)$ & $0(0 \%)$ & \\
\hline \multicolumn{4}{|l|}{ Education } \\
\hline Less than University Education & $460(56.4 \%)$ & $189(56.1 \%)$ & 0.548 \\
\hline University Education & $330(40.5 \%)$ & $148(43.9 \%)$ & \\
\hline Missing & $25(3.1 \%)$ & $0(0 \%)$ & \\
\hline \multicolumn{4}{|l|}{ Monthly Household Income (Euros/Month) } \\
\hline Mean (SD) & $2910(2250)$ & $3190(2060)$ & 0.0457 \\
\hline Median [Min, Max] & $2600[0,35000]$ & $3000[0,19000]$ & \\
\hline Missing & $142(17.4 \%)$ & $0(0 \%)$ & \\
\hline \multicolumn{4}{|l|}{ Physical Health } \\
\hline Mean $(\mathrm{SD})$ & $49.2(8.62)$ & $49.4(8.59)$ & 0.66 \\
\hline Median [Min, Max] & $51.9[18.3,65.9]$ & $52.4[12.5,65.2]$ & \\
\hline Missing & $211(25.9 \%)$ & $0(0 \%)$ & \\
\hline \multicolumn{4}{|l|}{ Core Self Evaluations } \\
\hline Mean $(\mathrm{SD})$ & $3.59(0.665)$ & $3.66(0.672)$ & 0.146 \\
\hline Median [Min, Max] & $3.50[1.08,5.00]$ & $3.67[1.67,5.00]$ & \\
\hline Missing & $231(28.3 \%)$ & $0(0 \%)$ & \\
\hline \multicolumn{4}{|l|}{ Retirement Intentions } \\
\hline Mean (SD) & $1.88(1.17)$ & $1.81(1.15)$ & 0.352 \\
\hline Median [Min, Max] & $1.25[1.00,5.00]$ & $1.00[1.00,5.00]$ & \\
\hline Missing & $217(26.6 \%)$ & $0(0 \%)$ & \\
\hline \multicolumn{4}{|l|}{ Subjective Age } \\
\hline Mean (SD) & $37.6(10.5)$ & $38.5(10.0)$ & 0.216 \\
\hline Median [Min, Max] & $36.3[18.0,65.0]$ & $38.3[20.0,64.8]$ & \\
\hline Missing & $244(29.9 \%)$ & $0(0 \%)$ & \\
\hline
\end{tabular}


Table 2. Correlations Among Study Variables.

\begin{tabular}{|c|c|c|c|c|c|c|c|c|c|c|c|c|c|c|c|c|c|c|c|}
\hline & Variable & 1. & 2. & 3. & 4. & 5. & 6. & 7. & 8. & 9. & 10. & 11. & 12. & 13. & 14. & 15. & 16. & 17. & 18. \\
\hline 1. & T1 Chronological Age & - & & & & & & & & & & & & & & & & & \\
\hline 2. & T1 Sex & -.185 & - & & & & & & & & & & & & & & & & \\
\hline 3. & T1 Education & -.033 & .010 & - & & & & & & & & & & & & & & & \\
\hline 4. & T1 Income (Euros/Month) & .057 & -.050 & .266 & - & & & & & & & & & & & & & & \\
\hline 5. & T1 Physical Health & -.165 & -.066 & .066 & .022 & .830 & & & & & & & & & & & & & \\
\hline 6. & T1 Core Self Evaluations & .403 & -.019 & .032 & .071 & .132 & .602 & & & & & & & & & & & & \\
\hline 7. & T1 Subjective Age & .862 & -.132 & -.049 & -.008 & -.226 & .317 & .880 & & & & & & & & & & & \\
\hline 8. & T2 Subjective Age & .870 & -.116 & -.028 & .011 & -.258 & .318 & .917 & .882 & & & & & & & & & & \\
\hline 9. & T3 Subjective Age & .877 & -.117 & -.037 & .013 & -.246 & .323 & .928 & .948 & .878 & & & & & & & & & \\
\hline 10. & T4 Subjective Age & .855 & -.113 & -.083 & -.019 & -.209 & .331 & .920 & .909 & .924 & .887 & & & & & & & & \\
\hline 11. & T5 Subjective Age & .858 & -.131 & -.072 & .010 & -.223 & .328 & .913 & .937 & .930 & .926 & .879 & & & & & & & \\
\hline 12. & T6 Subjective Age & .865 & -.107 & -.057 & .020 & -.246 & .327 & .922 & .950 & .949 & .936 & .950 & .877 & & & & & & \\
\hline 13. & T1 Retirement Intentions & .264 & -.062 & -.035 & .069 & -.335 & -.175 & .261 & .281 & .269 & .277 & .280 & .287 & .942 & & & & & \\
\hline 14. & T2 Retirement Intentions & .169 & -.119 & -.023 & .083 & -.306 & -.213 & .127 & .154 & .170 & .158 & .167 & .152 & .711 & .942 & & & & \\
\hline 15. & T3 Retirement Intentions & .230 & -.013 & -.033 & .066 & -.258 & -.179 & .203 & .238 & .236 & .237 & .254 & .231 & .700 & .709 & .944 & & & \\
\hline 16. & T4 Retirement Intentions & .194 & -.082 & .006 & .106 & -.220 & -.197 & .167 & .170 & .175 & .187 & .198 & .172 & .663 & .695 & .735 & .938 & & \\
\hline 17. & T5 Retirement Intentions & .203 & -.107 & .001 & .088 & -.321 & -.211 & .206 & .208 & .227 & .227 & .234 & .229 & .691 & .707 & .738 & .747 & .940 & \\
\hline 18. & T6 Retirement Intentions & .219 & -.092 & -.032 & .047 & -.292 & -.180 & .233 & .226 & .222 & .255 & .255 & .238 & .717 & .713 & .719 & .764 & .767 & .953 \\
\hline
\end{tabular}

Note. $n=337 . r_{x y}=|-.107|$ are $p<.05$. Where relevant (i.e., for multi-item scales) coefficient alpha reliability estimates are listed in the diagonal. T1 Sex coded as $1=$ Male; $2=$ Female; T1 Education coded as $0=$ less than university education; $1=$ university education 
Table 3. Summary of Measurement Invariance Models

\begin{tabular}{llllllllll}
\hline \multicolumn{1}{c}{ Model } & $\boldsymbol{\chi}_{\text {scaled }}$ & df & p-value & CFI & RMSEA & SRMR & \multicolumn{1}{c}{$\boldsymbol{\Delta} \boldsymbol{\chi}^{\mathbf{2}}$} & \multicolumn{1}{c}{$\boldsymbol{\Delta d f}$} & p-value \\
\hline Configural & 1420.205 & 894 & $<.001$ & 0.976 & 0.044 & 0.055 & - & - & - \\
Metric & 1441.678 & 924 & $<.001$ & 0.976 & 0.043 & 0.056 & 23.720 & 30 & 0.785 \\
Strong & 1462.706 & 954 & $<.001$ & 0.977 & 0.042 & 0.056 & 17.170 & 30 & 0.970 \\
Strict & 1473.156 & 964 & $<.001$ & 0.977 & 0.042 & 0.057 & 9.625 & 10 & 0.474 \\
\hline
\end{tabular}


Table 4. Summary of Relevant RI-CLPM Parameter Estimates

\begin{tabular}{|c|c|c|c|c|c|c|c|c|c|}
\hline \multirow[b]{2}{*}{ Predictor } & & \multirow[b]{2}{*}{ Outcome } & \multirow[b]{2}{*}{$\boldsymbol{B}_{\text {raw }}$} & \multirow[b]{2}{*}{$S E_{B}$} & \multirow[b]{2}{*}{$Z$} & \multicolumn{4}{|c|}{$95 \% \mathrm{CI}$} \\
\hline & & & & & & p-value & Lower & Upper & $\boldsymbol{B}_{\text {std }}$ \\
\hline Subjective Age $T_{k}$ & $\rightarrow$ & Subjective Age $T_{k+1}$ & .043 & .047 & .906 & .365 & -.050 & .136 & .050 \\
\hline Retirement Intentions $\mathrm{T}_{\mathrm{k}}$ & $\rightarrow$ & Subjective Age $T_{k+1}$ & .297 & .136 & 2.177 & .029 & .030 & .563 & .074 \\
\hline Retirement Intentions $T_{k}$ & $\rightarrow$ & Retirement Intentions $T_{k+1}$ & .082 & .055 & 1.490 & .136 & -.026 & .190 & .086 \\
\hline Subjective Age $T_{k}$ & $\rightarrow$ & Retirement Intentions $T_{k+1}$ & .003 & .007 & .494 & .621 & -.010 & .016 & .016 \\
\hline
\end{tabular}

Note. T = "time" 
Figure 1. Graphical Representation of RI-CLPM and Summary of Relevant Parameter Estimates.

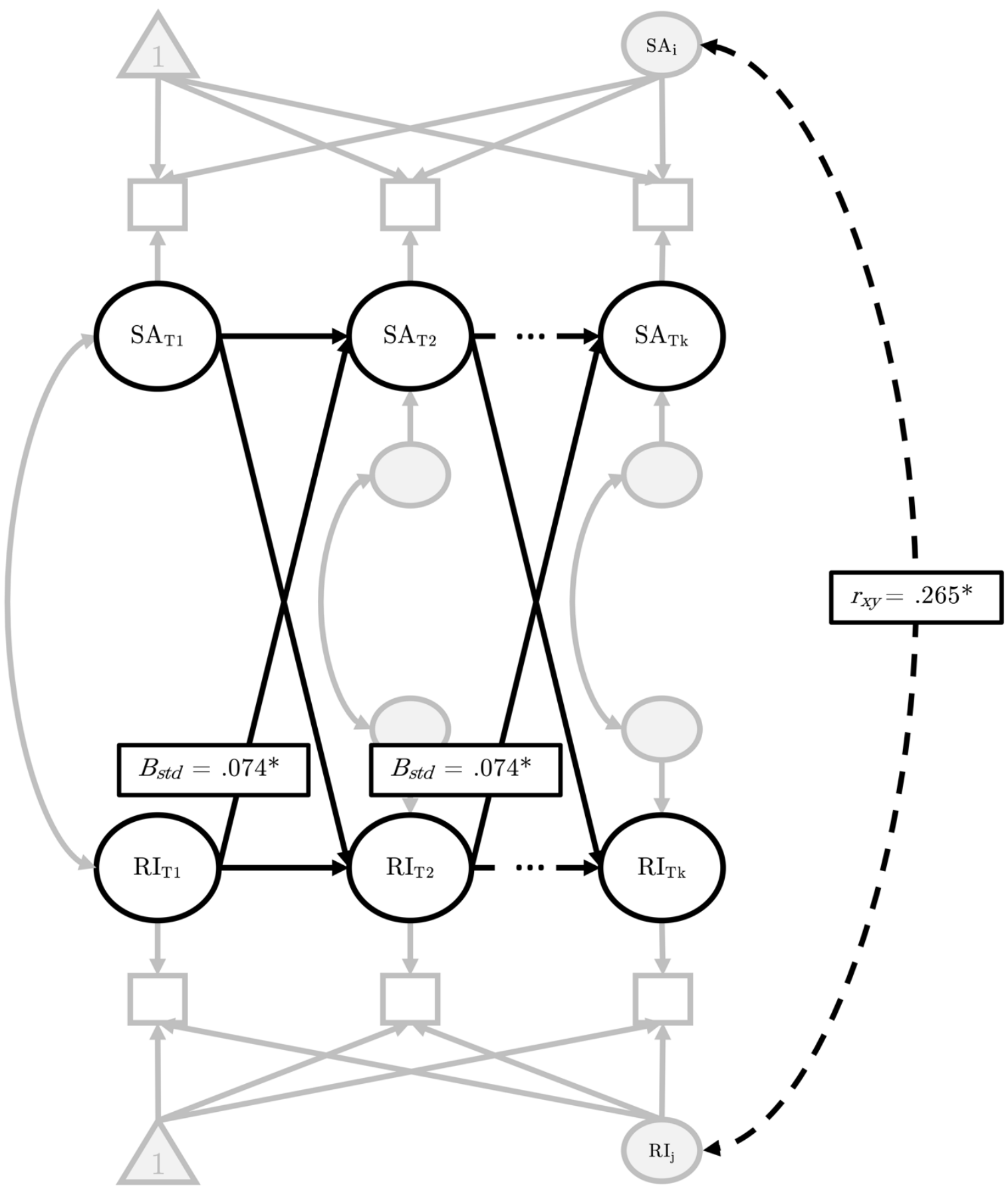

Note. For the sake of parsimony, only statistically significant parameter estimates are represented here. Dashed line indicates correlation among random effects. 
Figure 2. Graphical Representation of Means and 95\% Confidence Intervals of Retirement Intentions Over Time by Age Group (Panel “A”) and the Distribution of Retirement Intentions Over Time by Age Group (Panel “B”).

\section{(A)}

Means and 95\% Confidence Intervals of Retirement Intentions Over Time by Age Group

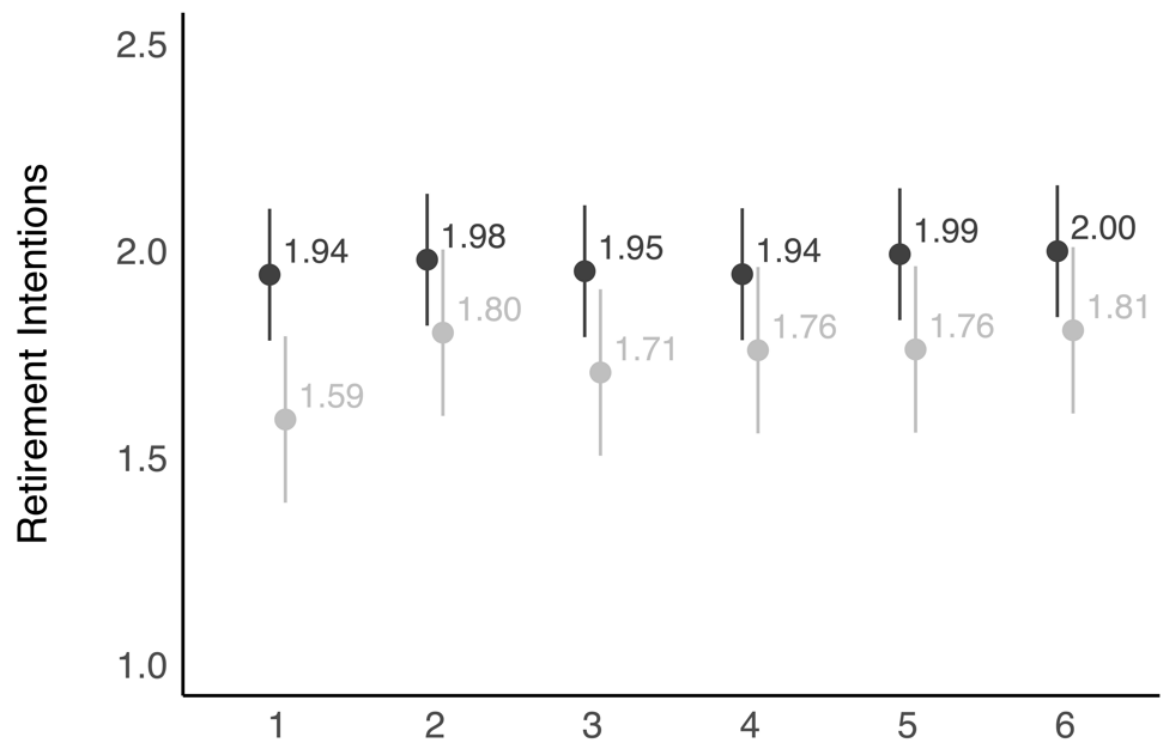

Age Group

Older $(40+)$

Younger $(<40)$

\section{Time}

(B)

Distribution of Retirement Intentions Over Time by Age Group

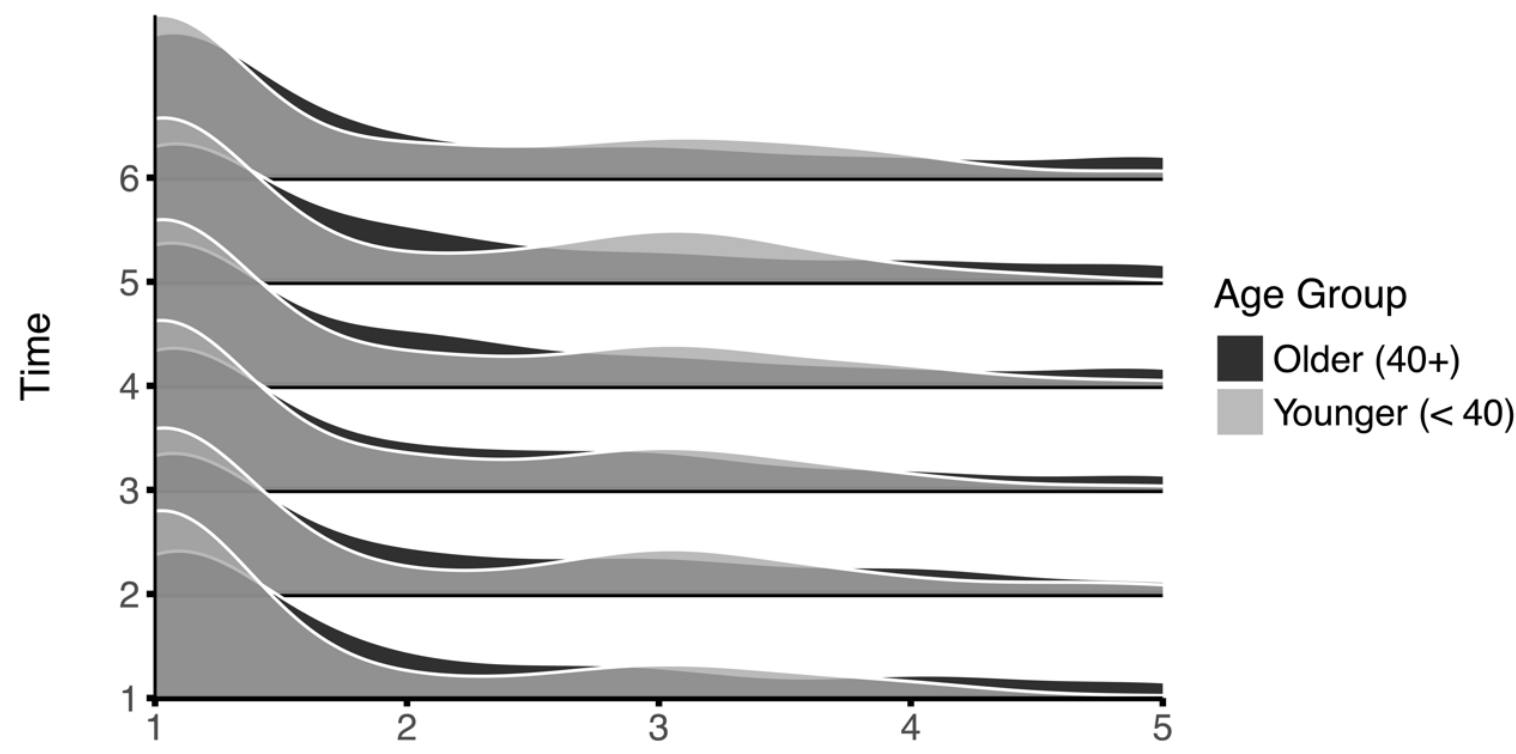

Retirement Intentions 